\title{
AS UNIDADES LITOESTRATIGRÁFICAS DA PASSAGEM JURÁSSICO-CRETÁCEO NO NORDESTE DO BRASIL
}

\author{
IGNACIO MACHADO BRITO*
}

\begin{abstract}
The boundary between the Jurassic and the Cretaceous in Brazil is not well defined. During this time, the geological history of the Brazilian continental marginal basins is related to the initial stages of the separation of the Brazilian and African plates: the continental or pre-rift (Donjoaniano stage) and the lacustrine or rift phase (Bahiano stage). The lack of marine fossils does not allow an exact correlation with the standard stratigraphic column but the study of fresh water ostracodes, polen and fishes, common to Brazil and West Africa basins, suggest the boundary JurassicCretaceous in the upper part of the Donjoaniano stage during the deposition of the Sergi-SerrariaMissão Velha sandstone.
\end{abstract}

INTRODUÇÃo O limite entre o Jurássico e o Cretáceo, considerado pela maioria dos autores como a passagem do Portlandiano ou Titoniano para o Berriasiano, não pode ser determinado com precisão segundo os conhecimentos atuais, porque todos os terrenos anteriores à fase francamente marinha, bem representados nas bacias costeiras, identificados a partir do Albiano Inferior ou pelo menos do Aptiano Superior, ainda não foram classificados nos andares da coluna geológica internacional. Maiores dificuldades são observadas nas outras bacias, onde os terrenos em questão ainda não estão convenientemente colocados no Jurássico ou no Cretáceo. Nas bacias paleozóicas, o problema torna-se ainda maior por causa das intrusões que ocorreram entre o Jurássico Superior e o Cretáceo Inferior.

Várias subdivisões cronoestratigráficas foram propostas para o Mesozóico das bacias costeiras, inicialmente por técnicos da Petrobrás (Viana 1980) e posteriormente por Brito \& Campos $(1982,1983)$, que consideram o tempo de deposição da fase lacustre inicial como andar Donjoaniano; o relativo à fase lacustre do rifte como andar Bahiano, proposto por Hartt (1870, p. 556) como grupo; e, finalmente aquele correspondente ao tempo de deposição da fase salífera e de seus depósitos síncronos como andar Alagoano.

$\mathrm{O}$ andar Donjoaniano é representado por uma seqüência de folhelhos vermelhos, de origem lacustre, intercalados e sobrepostos por arenitos médios a grossos, de sistemas fluviais anastomosados, que ocuparam uma grande-área englobando as posteriormente delimitadas bacias do RecôncavoTucano-Jatobá, Sergipe-Alagoas, Araripe e Gabão.

No Recôncavo-Tucano-Jatobá, os folhelhos vermelhos com intercalação de arenitos recebem o nome de Formação Aliança. Seus equivalentes nas bacias de Sergipe-Alagoas e Araripe são, respectivamente, as formações Bananeiras e Brejo Santo. Os arenitos sobrepostos aos folhelhos vermelhos superiores vão constituir a Formação Sergi na Bacia do Recôncavo, Serraria na de Sergipe-Alagoas e a parte inferior da Missão Velha na Bacia do Araripe.

Nas três bacias brasileiras, essas unidades vêm sendo grupadas de maneira bastante desigual. Assim, no RecôncavoTucano-Jatobá vão constituir o Grupo Brotas; na de Sergipe-Alagoas, juntamente com as formações Batinga e Aracaré, de idade permiana, essas unidades têm sido estudadas em conjunto pelos técnicos da Petrobrás no Subgrupo Igreja Nova, que, reunido com as formações da fase de rifte (Sub- grupo Coruripe), constituiriam o Grupo Baixo São Francisco; e na Bacia do Araripe, juntamente com os arenitos paleozóicos inferiores e com as formações superiores e discordantes, estariam constituindo o Grupo Araripe.

GRUPO BROTAS As formações continentais anteriores à fase rifte, na Bacia do Recôncavo-Tucano-Jatobá, vão constituir o Grupo Brotas, de idade entre o Jurássico ao Eocretáceo. Sua denominação é derivada da localidade de Brotas, situada a $6 \mathrm{~km}$ a oeste de Mata da Aliança, no Recôncavo.

Pack \& Almeida (1947, p.79) com o nome de Formação Brotas, caracterizam as red beds do Recôncavo, que já tinham sido denominadas de "camadas vermelhas da Aliança". Dizem ainda que Shaerer, em 1942, já havia utilizado o nome Formação Brotas, que, posteriormente, Barnes (1950) subdividiu em Folhelho Aliança e Arenito Sergi.

Segundo Oliveira (1956, p.51), a Formação Brotas foi depositada durante rápida submergência e pode ser correlacionada com a Formação Motuca da Bacia do Maranhão.

No estudo da Bacia do Recôncavo, realizado pela Petrobrás em 1958, a Formação Brotas foi elevada à categoria de grupo, subdividido nas formações Aliança e Sergi.

Nos extremos da bacia, o grupo foi estudado por diversos autores, tais como Carvalho (1965, p.13), que, mapeando a Bacia de Almada, a norte de Ilhéus, comenta que sua parte inferior (Formação Aliança) não está representada, pelo menos em superfície; e Ghignone (1963) diz, em estudos sobre o flanco oriental do Tucano Norte, que "no grupo Brotas não há passagem gradual da Formação Aliança para a Formação Sergi, o que ocorre é uma abrupta quebra litológica entre uma e outra formação, que invalida a reunião dessas formações absolutamente distintas como constituintes de um grupo". Diz ainda esse autor: "A formação Sergi, apesar de ser representada por afloramentos típicos na área sudoeste da Bacia de Jatobá, não mais pode ser mapeada a nordeste da cidade de Inajá. Portanto existe a possibilidade de a Formação Sergi não ter sido depositada, ter sido erodida naquela área, e no poço de Ibirim (Imst-1-Pe), o que foi considerado Sergi, ser na realidade sedimentos Candeias inferior". Almeida (1967, p. 150) assinala na Bacia do Jatobá tanto a Formação Aliança quanto a Formação Sergi.

Informações e resumos sobre o Grupo Brotas são apre- 
sentados por diversos autores, entre os quais se destacam Fonseca. (1966, p.50), Braun (1970, p.111) e Viana et al. (1971, p.161).

\section{FORMAÇÃo ALIANÇA A Formação Aliança consti-} tui a base da seqüência mesozóica da Bacia do RecôncavoTucano-Jatobá. Sua denominação foi tomada da localidade de Mata da Aliança, próxima de Amélia Rodrigues, Bahia, onde, na rodovia BR-324 entre os km 75 e 80, está a seçãotipo. A unidade é constituída, em sua parte basal, de conglomerados e arenitos conglomeráticos seguidos de folhelhos vermelho-tijolo, com ocasionais intercalações de siltitos que vão constituir o Membro Afligidos, que diminui de espessura em direção ao norte. Na parte média, em contato um tanto nítido, encontram-se arenitos geralmente avermelhados podendo ser cinza ou marrom, subarredondados, regularmente classificados, com alguma estratificação cruzada, que vão constituir o Membro Boipeba, que também diminui de espessura do sul para o norte. Na parte superior da formação, a litologia apresenta novamente folhelhos vermelhotijolo com ocasionais intercalações de calcário microcristalino com possíveis intercalações de arenitos,vermelho-acastanhados, finos a sílticos, no topo da seqüência, que vão constituir o Membro Capianga.

Os membros Afligidos e Capianga seriam os registros da sedimentação lacustre enquanto o Membro Boipeba e a Formação Sergi indicariam períodos sedimentares, onde as taxas de deposição suplantavam as de subsidência (Medeiros \& Pontes 1981, p.3). A Formação Aliança é perfeitamente correlacionada com a Formação Bananeiras, da Bacia de Sergipe-Alagoas, Brejo Santo, da Chapada do Araripe, Agoula e M'Vone, da Bacia do Gabão. Com a mesma denominação foi, também, assinalada na pequena Bacia de Mirandiba, no Estado de Pernambuco. Seu contato inferior com ò embasamento e com as formações Tacaratu, Inajá e Santa Brígida é discordante e o superior com a Formação Sergi é gradativo.

A denominação dos membros é derivada da estação de Afligidos, $19 \mathrm{~km}$ a oeste de Santo Amaro, da Fazenda Boipeba no município de Catu, e da vila Capianga, no município de Entre Rios. Nessas duas últimas localidades, as seçõestipo foram definidas em sondagens.

A Formação Aliança aflora principalmente nos bordos oeste das bacias do Recôncavo e Tucano Sul, leste de Tucano e sul da Bacia do Jatobá, em contato com os sedimentos do Paleozóico. Há diversas ocorrências isoladas em outras áreas.

Os fósseis são representados por ostracodes da biozona Bisulcocypris pricei, constituída por microfósseis não só dessa espécie mas também por $B$. uninodosa e algumas formas de Metacypris, Candona e Darwinula.

No Relatório do Conselho nacional do Petróleo de 1944 (De Golyer 1946, p.68), num estudo sobre a geologia e estratigrafia do Recôncavo, são descritas as camadas vermelhas (red beds) sotopostas à Série Bahia: "Entre os km 108-110 da rodovia Salvador-Feira de Santana e na VFFLB (Viação Férrea Federal Leste Brasileira), entre as estações de Sergi e Afligidos, ocorrem camadas vermelhas (red beds) nas proximidades do contato Cretáceo-Cristalino, com cores vermelho intenso e chocolate, compostas de arenitos de grão fino, de modo geral muito bem estratificados, apresentando-se em alguns locais maciços e, em outros, com estratificação cruzada, siltitos e folhelhos sílticos. Os mergulhos vão até $35^{\circ}$ e parecem muito perturbados, deixando antever a existência de falhas. A posição exata dessas camadas vermelhas (red beds) ainda não está perfeitamente definida, parecendo tratar-se de sedimentos cretáceos ou jurássicos, o que será resolvido com a execução do programa de detalhes entre Afligidos e Lapa".

Pack \& Almeida (1947, p.79) descrevem com o nome de Formação Brotas a "grande série de camadas vermelhas (red beds), coberta por formações cretáceas e que se estende pela maior parte do recôncavo, constituindo, ao que parece, os sedimentos mais antigos da área". Dizem ainda que esses sedimentos "eram a princípio denominados camadas vermelhas de Aliança" e que o nome Formação Brotas proposto já hávia sido sugerido pelo geológo H.K. Shearer. Definem a seção geológica característica na rodovia Salvador-Feira de Santana "nas proximidades do arraial de Brotas, e a cerca de 6 quilômetros a oeste da vila de Mata da Aliança", apresentam uma descrição sumária da unidade e estimam sua espessura em $780 \mathrm{~m}$, com base em sondagem.

Depois de diversos estudos sobre a Bacia do Recôncavo, realizados pela Petrobrás e apresentados em relatórios internos, Fonseca (1966, p.59), dentro do Grupo Brotas, estuda a unidade já como Formação Aliança descrevendo resumidamente sua litologia, espessura, idade e paleontologia, origem e correlação.

Viana et al. (1971, p.161) na revisão estratigráfica da Bacia do Recôncavo-Tucano formalizam a subdivisão litoestratigráfica da Formação Aliança em Membro Afligidos, o mais inferior, Membro Boipeba, o médio, e Membro Capian. ga, o superior.

Os terrenos estudados por Melo Junior \& Oliveira (1939, p.25) com o nome de Formação Jacu, originalmente descritos por Branner (1913, p. 622), são hoje considerados como pertencentes à Formação Aliança. Nesse trabalho, os autores estudam "alguns afloramentos de sedimentos muito parecidos com os da série da Estância, de Sergipe, contendo Alethopteris branneri". Com certa reserva, colocam a formação do Permiano, ressaltando que "pode ser que no futuro sejam tais terrenos considerados cretáceos, mas de um grupo inferior ao do Recôncavo". A área estudada foi a de Araci, no flanco ocidental da Bacia de Tucano Sul e a denominação da "formação" deriva da Fazenda Jacu, 6 km distante da citada localidade, onde, numa cacimba, foi estudada uma seção de quase $20 \mathrm{~m}$ de arenito amarelado tendendo para o vermelho a $3,30 \mathrm{~m}$ de folhelho preto-azulado. Depois de descrever e comentar a geologia da área e de fazer algumas comparações, os autores dizem que "entre Araci e Tucano é quase certo que se trata da mesma camada". Quanto aos folhelhos, afirmam que são muito ricos em fósseis, mas que é difícil conseguir exemplares perfeitos porque a rocha é bastante friável. Esses fósseis são bem representados pela pteridófita Alethopteris branneri, descrito por David White em 1913. Segundo Oliveira (in Melo Junior \& Oliveira 1939 , p.72), Alethopteris também é encontrada no Jurássico Superior ou Cretáceo Inferior da India e que parece "não ser fora de propósito referir o nosso Alethopteris branneri a uma idade mais ou menos próxima da Série Bahia, isto é, Wealdeniana".

Em recentes estudos da região de Araci, realizados pela Petrobrás, os terrenos da área foram mapeados como do Grupo Brotas, em blocos falhados dentro do cristalino, no bordo da bacia, onde a Formação Aliança não apresenta o membro inferior Afligidos.

Ghignone (1979, p.53) diz que mapeou, em 1956, a região de Araci e teve oportunidade de visitar o local onde 
se situava a Fazenda Jacu, tornando-se evidente que as plantas fósseis ali coletadas o foram em folhelhos vermelhos da Formação Aliança.

FORMAÇÃo SERGI A Formação Sergi constitui a seqüência arenosa sobreposta à Formação Aliança na Bacia do Recôncavo-Tucano-Jatobá. Sua denominação foi tomada do vale do Rio Sergi, onde, ao longo do canyon deste rio e da estrada de ferro, $7 \mathrm{~km}$ a nordeste de Santo Amaro, foi definida a seção tipo.

A unidade é constituída de arenitos finos a conglomeráticos de coloração geralmente pardo-amarelada a creme. Varia de arenitos mal a regularmente classificados, subangulares a subarredondados, argilosos, pouco feldspáticos, raramente micáceos e caulínicos. Localmente há níveis conglomeráticos com seixos de sílex.

A Formação Sergi aflora nas mesmas áreas da Formação Aliança, mas, para o sul, se estende até a Bacia do Almada. O contato inferior com a Formação Aliança é gradacional e o superior com as Formações do Grupo Bahia é discordante. Seus fósseis são representados por troncos de árvores concentrados em localidades como Cocorobó, a oeste de Jeremoabo, na Bacia de Tucano, onde os citados troncos são abundantes e de grande porte. São atribuídos ao gênero Dadoxylon mas nunca foram convenientemente estudados.

Esta unidade litológica constitui a parte superior da seqüência dos continentes onde correntes transportaram sedimentos para dentro dos lagos e formaram leques subaqữosos ao lado de sedimentação eólica, onde, dentro das camadas com estratificação cruzada, podem ser observados ventifactos.

Segundo Moreira da Silva (1966), a seção inferior da formação foi transportada por correntes de direção NNW e a superior, por correntes de direção SSE.

A Formação Sergi é correlacionada com a Formação Serraria, da Bacia de Sergipe, com a parte inferior da Formação Missão Velha, da Chapada do Araripe, e com a Formação N'Dombo, da Bacia do Gabão. O contato inferior com a Formação Aliança, como já foi dito, é gradativo, enquanto o superior com o Grupo Bahia é discordante.

Foi assim descrita pela primeira vez no Relatório de 1946 do Conselho Nacional do Petróleo (Taylor 1948, p.155): "No topo da Formação Brotas existe uma camada de arenito a que é dado o nome de arenito Sergi, designação muito usada nos trabalhos superficiais e subsuperficiais. Esse arenito está exposto na garganta do rio Sergi, a oeste da cidade de Santo Amaro, onde ocorre a seção típica; os afloramentos começam no quilômetro 89 da Viação Férrea Federal Leste Brasileiro, 7 quilômetros a oeste de Santo Amaro e continuam para oeste até a estação Sergi em extensão aproximada de 5 quilômetros. $\mathrm{O}$ arenito Sergi é de sedimentação espessa e maciça, com muita estratificação cruzada, inclinação pequena, cores branca, vermelha, púrpura e castanha, granulação média a grossa, arcósica, friável e com feição de conglomerado".

A denominação Sergi aparece nos relatórios do Conselho Nacional do Petróleo subseqüentes como a camada superior da Formação Brotas e subdividida nos horizontes inferior, médio e superior.

Após diversos estudos sobre a Bacia do Recôncavo, realizados pela Petrobrás e constantes de vários relatórios internos, Fonseca (1966, p.59) estuda a unidade já como Formação Sergi, na parte superior do Grupo Brotas, descrevendo, assim como na Formação Aliança, sua litologia, espessura, origem e correlação.

Viana et al. (1971, p.162) propõem formalmente a designação Sergi para definir o pacote sedimentar imediatamente acima da Formação Aliança e imediatamente abaixo do que denominaram de Grupo Santo Amaro.

FORMAÇÃo BANANEIRAS A Formação Bananeiras é constituída essencialmente de clạ́sticos finos geralmente vermelhos, acastanhados ou arroxeados, raramente esverdeados. São folhelhos, argilitos e siltitos. Próximo da base da unidade foram observados turboglifos e gretas de contração, além de intercalações calcíferas gradando a calcários avermelhados com aglomerações de ostracodes e também delgadas intercalações de arenitos finos, argilosos e avermelhados.

Excelentes afloramentos podem ser vistos em cortes na rodovia BR-101, entre Carmópolis e Propriá, no km 31,5 e, principalmente, no $\mathrm{km} 12,5$, onde se observa o contato com a Formação Serraria, que lhe é sobreposta, indicando a progradação do sistema fluvial anastomosado sobre um lago.

Chaves et al. (1963, p.25) propuseram a Formação Bananeiras "para designar o pacote de folhelhos vermelhos violáceos sobrepostos aos arenitos, folhelhos e sílex da Formação Aracaré e sotopostos à massa de arenitos grosseiros da Formação Serraria".

Schaller $(1969$, p. 32) propõe a formalização do nome Formação Bananeiras e indica a mesma seção-tipo proposta pelos autores supra-citados. Comenta a litologia, comportamento estratigráfico e a idade da formação, que atribui ao Cretáceo Inferior ou Jurássico Superior, na zona de amplitude do ostracodes "Metacypris" sp. 3. Diz ainda que, com base na microfauna, pode ser correlacionada à idade da fácies Wealden.

Nesse mesmo trabalho, o autor propõe a Formação Candeeiro, constituída de arenitos brancos a cinza róseos e avermelhados, finos a médios, com interestratificações grossas, localmente contendo grânulos e seixos de sílex subangulares. Foi definida com base em sondagens e a seção tipo escolhida foi o intervalo entre 1.373 e $1.435 \mathrm{~m}$ do poço Candeeiro, CO-1-Al, em Alagoas. Esta unidade, provavelmente uma fácies grossa da Formação Bananeiras, era conhecida somente em subsuperfície, na área entrẹ o Rio Pacatuba até as proximidades de São Miguel dos Campos.

Recentemente, no Roteiro Geológico da Bacia de Sergipe-Alagoas, elaborado por técnicos da Petrobrás, em 1980, um afloramento da unidade em questão, situado a $3,3 \mathrm{~km}$ da rodovia BR-101, em corte da estrada para o povoado de Alagoinhas, próximo de Igreja Nova, foi descrito em detalhe. Apresenta duas fácies distintas. A inferior, com arenitos eólicos com estratificação cruzada e a superior com folhelhos, arenitos e siltitos com rápidas mudanças laterais de fácies tidas pelos sedimentólogos da Petrobrás como de sedimentação marinha de barra de plataforma.

FORMAÇÃo SERRARIA A Formação Serraria é constituída de arenitos brancos, amarelados, acinzentados e avermelhados, de granulação média a grossa, mal selecionados com grãos geralmente subangulares e em alguns pontos conglomeráticos: Localmente, há níveis de cascalhos e de folhelhos sílticos e, na base, intergradação com os folhelhos vermelhos da Formação Bananeiras.

Bons afloramentos podem ser vistos nos $\mathrm{km} 28$ e 12,5 da rodovia BR-101, entre Carmópolis e Propriá, Sergipe, e 
entre 0 povoado de Alagoinhas e Igreja Nova, no $\mathrm{km} \mathrm{21,1}$ da BR-101, em Alagoas.

Chaves et al. (1963, p.28) propuseram o nome Formação Serraria "para designar a massa de arenitos médios a grosseiros com estratificação cruzada sobrepostos aos folhelhos vermelhos da Formação Bananeiras e sotopostos aos folhelhos, siltitos e arenitos intercalados da Formação Barra de Itiúba".

O nome da formação derivia da localidade de Serraria, às margens do canal do Rio Boacica, próximo da Ipiranga, cerca de $6 \mathrm{~km}$ ao sul e ligeiramente a oeste da cidade de Igreja Nova, Alagoas, onde estão otimamente expostos cerca de 80 a $100 \mathrm{~m}$ da parte inferior da formação. Os autores mencionam, ainda, outros afloramentos expostos nos vales a noroeste de Alagoinhas, na estrada nova Propriá-Japoatã, e nas margens da estrada Malhada dos Bois-Bananeiras, sem apresentarem uma única seção-tipo.

Schaller $(1969$, p.34) propõe a formalização do nome Formação Serraria e como seção-tipo escolhe os afloramentos situados próximos do povoado de Serraria, às margens do Rio Boacica. Comenta a litologia, o comportamento estratigráfico e os poucos fósseis encontrados na unidade.

\section{FORMAÇÃO BREJO SANTO Os folhelhos, argilas cal-} cíferas e margas, de coloração variegada com tonalidades castanhas, sobrepostos discordantemente aos arenitos grossos da Formação Cariri vão constituir a Formação Brejo Santo, com uma espessura estimada em $50 \mathrm{~m}$. Sua área de afloramento localiza-se a leste da Chapada do Araripe, na região de Brejo Santo, Mauriti, Milagres e Missão Velha. Em diversos trabalhos, a unidade foi considerada simplesmente como a parte basal da Formação Missão Velha.

Braun (1966, p.38) diz que "na realidade a Formação Missão Velha (de Beurlen) inclui duas unidades litológica e geneticamente distintas. A inferior constituída de argilitos, folhelhos, siltitos e arenitos finos, castanho-avermelhados com intercalações de lâminas de aragonita e calcário ostracoidal". Estende para a unidade a denominação de Formação Aliança e identifica ostracodes que, segundo o autor, justificam a utilização desse nome para a Bacia do Araripe, o que é seguido por outros autores.

Gaspary \& Anjos (1964) e Caldasso (1967), com o nome de Formação Brejo Santo, separam os folhelhos, argilitos calcíferos e margas da base da Formação Missão Velha de Beurlen (1962, 1963), denominação tirada da cidade de Brejo Santo, no Ceará. Os sedimentos apresentam-se em camadas praticamente horizontais e em discordância com a Formação Cariri, que lhes sotopõe, e em concordância com a Formação Missão Velha, que lhes sobrepõe.

A Formação Brejo Santo vem sendo correlacionada, por diversos autores, com a Formação Aliança da Bacia do Recôncavo-Tucano-Jatobá. Autores, como Beurlen (1971) e Brito (1979), utilizaram a denominação Formação Aliança para a Formação Brejo Santo.

FORMAÇÃO MISSÃo VELHA Os sedimentos sobrepostos à Formação Brejo Santo, caracterizados por arenitos finos na base gradando para arenitos médios a grossos nas partes superiores, vão constituir a Formação Missão Velha, cuja espessura é da ordem de $200 \mathrm{~m}$ e as camadas são subhorizontais, muitas vezes com estratificação cruzada. Sua área de afloramento localiza-se a leste da Chapada do Araripe, nos munícipios de Barbalha, Juazeiro do Norte, Missão Velha e Porteiras.

Pelas características litológicas e pelas madeiras fósseis abundantes, a unidade é correlacionada com a Formação Sergi, do Donjoaniano.

Com o nome de Formação Missão Velha, Beurlen (1962, p.366) descreveu todo o pacote sedimentar sobreposto à Formação Cariri, originalmente estudado como "arenito inferior de Araripe" por Small (1913, p.33), "uma série de arenito molle vermelho e falsamente estratificado". Esse autor pioneiro apresenta as localidades onde ocorrem os melhores afloramentos nas proximidades de Crato, Barbalha, Juazeiro, Milagres e Brejo Santo. Comenta a semelhança desse arenito com os superiores, hoje denominados de Formação Exu, variações na litologia, presença de madeira fóssil e ‘de delgados leitos de carvão. No ano seguinte, Beurlen (1963, p.13) descreve a Formação Missão Velha detalhadamente e comenta as áreas de afloramento, litologia, variações faciológicas e chama a atenção para os troncos de árvore fósseis encontrados in situ.

Braun (1966, p.38) comenta que o trabalho de Beurlen (1962) peca por ele não ter considerado "a intensa tectônica tafrogênica que as afetou constituindo uma estrutura complexa de blocos falhados. Em conseqüência, parece-nos ter ele confundido os sedimentos argilosos que sotopõem a sua "Formação Missão Velha" com os que ocorrem intercalados nesta, tomando muitas vezes essa unidade pela sua "Formação Cariri". O autor adota o nome de Formação Sergi por sua identidade com a unidade litológica equivalente no Recôncavo.

Caldasso (1967, p.16) considera como Formação Missão Velha apenas os sedimentos da parte superior, arenosa, daquela estudada por Beurlen $(1962,1963)$ e diz que "a característica principal desses sedimentos é a estratificação cruzada e sua coloração vermelha, que parece ser de alteração". Correlaciona-se com os arenitos da Formação Sergi do Recôncavo pela presença de madeiras fósseis e características litológicas.

Silva (1967, p.15) sumariza os dados da Formação Missão Velha e comenta que "na parte inferior da formação ocorrem níveis de folhelho argiloso, contendo calcário, e na parte superior desta formação ocorrem grandes e numerosos troncos de madeira Podocarpus (coníferas), que parecem estar in situ".

Beurlen \& Mabesoone (1969, p.25) citam ocorrências de manchas isoladas, observadas na Bacia do Barro, com pequenas relíquias de sedimentos da Formação Missão Velha.

Barbosa (1970, p.23) diz que "na zona da Formação Missão Velha de Buerlen encontramos realmente duas formações: em baixo, camadas Aliança (com ostracodes e Estherias típicas); acima, 200 metros de arenitos Sergi, com abundantes coníferas petrificadas".

Autores como Beurlen (1971) e Brito (1979), utilizaram para a unidade o nome de Formação Sergi.

A IDADE DO ANDAR DONJOANIANO As formações Aliança, Bananeiras e Brejo Santo apresentam as camadas fossilíferas mais antigas do Mesozóico das bacias costeiras do Brasil, representadas por uma associação de ostracodes lacustres, na qual predominam os gêneros Bisulcocypris e Metacypris, cujas espécies apresentam dimensões anormalmente reduzidas. Ao lado de $B$. pricei Pinto e Sanguinetti, principal forma-guia, encontra-se Darwinula cf. D. oblonga 
(Roemer), de dimensões anormais e razoavelmente freqüente (Viana 1980, p.833). Segundo Grekoff (1957), Darwinula oblonga é um ostracode do Jurássico Terminal. Os demais fósseis encontrados na associação, representados por conchostráceos e fragmentos de peixes, ainda não foram estudados.

Acima do nível dos ostracodes, os microfósseis são, segundo os conhecimentos atuais, inexistentes. Nos arenitos das formações Sergi, Serraria e Missão Vermelha são abundantes, em algumas localidades, troncos de árvores atribuídos a Dadoxylon bendery, mas que, na verdade, ainda não foram descritos.

Em camadas imediatamente superiores às dos mencionados troncos, nos folhelhos, aparece o gênero Cypridea, que, segundo Viana (1980), explode em um conjunto de espécies com características semelhantes e intimamente relacionados entre si. Muitos gêneros e espécies de ostracodes são encontrados a partir da base do andar Banıano, denominada por técnicos da Petrobrás andar Rio da Serra, que estaria cronologicamente situado na base do Cretáceo Inferior.
Os palinomorfos também são encontrados somente a partir da base do andar Bahiano, onde a zona de amplitude Applanopsis trilobatus indica o início das seqüências palinológicas. $\mathrm{O}$ referido esporomorfo é também encontrado no Cretáceo Basal do Egito. Seguem-se outras zonas palinológicas já bem definidas encontradas também em diversas bacias africanas a partir do Barremiano.

A fauna de vertebrados, relativamente abundante a partir da base do andar Bahiano, representada principalmente por peixes Semionotidae, Coelacantidae, Amiidae e Clupeidae e por reptéis crocodilianos, não fornece, segundo dados atuais, muitas informações a respeito das idades dos terrenos onde foi encontrada, a não ser os semionotídeos do gênero Lepidotes que podem indicar um intervalo do Jurássico Superior ao Cretáceo Inferior.

Pelos dados de que a Paleontologia dispõe, ainda um tanto insuficientes, a passagem Jurássico-Cretáceo no Nordeste do Brasil deve situar-se nos arenitos Sergi-Serraria-Missão Velha.

\section{REFERÊNCIAS BIBLIOGRÁFICAS}

ALMEIDA, A.C.F. - 1967 - Geologia das Bacias de Jatobá e Tucano Norte. Rio de Janeiro, Petrobrás, Colet. Relat. Expl. (I), Ciênc. Téc. Petrol., 3:145-155.

BARBOSA, O - 1970 - Geologia Econômica da parte da Região do Médio São Francisco, Nordeste do Brasil. Rio de Janeiro, DNPM/DFPM. 97p. (Bol. 140).

BARNES, B.E. - 1950 - Estado da Bahia - Geologia. Rio de Janeiro, Cons. Nac. Petróleo, p.93-100. (Relatório 1949).

BEURLEN, K. - 1962 - A Geologia da Chapada do Araripe. Rio de Janeiro, An Acad. bras. Ciênc., 34(3):365-370.

BEURLEN, K. - 1963 - Geologia e Estratigrafia da Chapada do Araripe. In: CONGR. BRAS. GEOL., 17 Recife, 1963. Recife, SBG. $47 \mathrm{p}$.

BEURLEN, K. - 1971 - Bacias sedimentares do Bloco Brasileiro. Natal, Estudos Sedimentológicos, 1(2):9-31.

BEURLEN, K. \& MABESOONE, J.M. - 1969 - Bacias cretáceas intracontinentais do Nordeste do Brasil. Campinas, Not. Geomorf., 9(18):19-34.

BRANNER, J.C. - 1913 - The Estancia beds of Bahia, Sergipe and Alagoas, Brazil. Am.J.Sci (Ser. 4), 35(210):619-631.

BRAUN, O.P.G. - 1966 - Estratigrafia dos sedimentos da parte interior da Região Nordeste do Brasil (Bacias de TucanoJatobá, Mirandiba e Araripe). Rio de Janeiro, Div. Geol. Mineral., DNPM, 236:75p.

BRAUN, O.P.G. - 1970 - A respeito do "Paleozóico da Bacia do Jatobá, Pernambuco". Rio de Janeiro, Miner Metal., 52(309):109-111.

BRITO, I.M. - 1979 - Bacias sedimentares e formaçōes pós-paleozóicas do Brasil. Rio de Janeiro, Ed. Interciência, 179 p.

BRITO, I.M. \& CAMPOS, D.A. - 1982 - O Cretáceo no Brasil. Rio de Janeiro, An. Acad. bras. Ciênc., 54(1):197-218.

BRITO, I.M. \& CAMPOS, D.A. - 1983 - The Brazilian Cretaceous. München, Zitteliana, 10:277-283.

CALDASSO, A.L.S. - 1967 - Geologia da Quadrícula E-094 Folha Crato. Recife, Sudene, Div. Geol. 35 p. (Série Geol. Reg. 3).

CARVALHO, K.W.B. - 1965 - Geologia da Bacia Sedimentar do Rio Almada. Rio de Janeiro, Bol. Téc. Petrobrás, 8(1):5-55.

CHAVES, H.; PERRELLA, J.M.L.; RICHTER, A.J. - 1963 - Relatório sobre o levantamento geológico do NE de Sergipe e SE de Alagoas. Maceió, Petrobrás/Serdeste, Setor de Exploração, Relatório 252 (Relatório 1805, inédito).

DE GOLYER, E.L. - 1946 - Estado da Bahia - Geologia. Rio de Janeiro, Cons. Nac. Petróleo, p. 61-76. (CNP, Rel. de 1944).

FONSECA, J.I. - 1966 - Geological Outline of the Lower Cretaceous Bahia Supergroup Brazil. In: WEST AFRICAN MICROPAL. COLL, 2 Ibadar, 1965. Proc... Ibadar. p. 49-79.

GASPARY, J. \& ANJOS, N.F.R. - 1964 - Estudo hidrogeológico de Juazeiro do Norte, Ceará. Recife, Sudene. 25p. (Série Hidrogeologia 3).
GHIGNONE, J.I. - 1963 - Geologia do Flanco Oriental da Bacia do Tucano Norte (Do Vaza-Barris ao São Francisco). Salvador, Petrobrás/Setor de Exploração, Relat. 688112 p. (Relatório 1812 , inédito).

GHIGNONE, J.I. - 1979 - Geologia dos Sedimentos fanerozóicos da Bahia. Salvador, Geologia e Recursos Minerais do Estado da Bahia. In: INDA, H.A. (ed.). Textos básicos, Coord. Prod. Min. Secret. Minas e Energia, Bahia, v.1, p. 23-117.

GREKOFF, N. - 1957 - Ostracodes du Bassin du Congo. Tervuren, Ann. Mus. Royal Congo Belge. Ser. 8. ${ }^{\circ}$, Sc. Geol., 19:97.

HARTT, C.F. - 1870 - Geology and physical geography of Brazil. Boston, Fields Osgood \& Co., 620 p.

MEDEIROS, R. \& PONTE, C. - 1981 - Roteiro Geológico da Bacia do Recôncavo (Bahia). Salvador, Petrobrás/Sepes, Diven, Sen-Ba. 63p.

MELO JUNIOR, J.L. \& OLIVEIRA, P.E. - 1939 - Novas localidades fossilíferas do Nordeste da Bahia. Rio de Janeiro, DNPM/DGM, 85p. (Bol. 103).

MOREIRA DA SILVA, N. - 1966 - Paleocorrentes deposicionais na Formação Sergi. Rio de Janeiro, Bol. Tec. Petrobrás, 9(2):181-209.

OLIVEIRA, A.I. - 1956 - Brazil in Handbook of South American Geology. In: JENKS, W.F., ed. Jenks. Geol. Soc. America. 62 p. (Mem. 65).

PACK, O.L. \& ALMEIDA, L.A. - 1947 - Estado da Bahia. Geologia. Rio de Janeiro, Cons. Nac. Petróleo p.71-88. (CNP, Rel. de 1945).

PETRI, S. \& FULFARO, V.J. - 1983 - Geologia do Brasil (Bacia do Parnaíba e remanescentes eopaleozóicos do Nordeste). São Paulo, EDUSP. p.58-59.

SCHALLER, H. - 1969 - Revisão estratigráfica da Bacia de Sergipe-Alagoas. Rio de Janeiro, Bol. Tec. Petrobrás, 12(1):21-86.

SILVA, M.D. - 1967 - Geologia estratigráfica da Chapada do Araripe. Recife, Univ. Fed. Pernambuco. 29 p. (Série Cient. Paleont. 2).

SMALL, H.L. - 1913 - Geologia e suprimento d'água subterrânea no Ceará e parte do Piauhy. Rio de Janeiro, Insp. Contra Seccas. 80 p. (Ser. 7, D., Publ. n. 25).

TAYLOR, E.F. - 1948 - Estado da Bahia. Geologia. Rio de Janeiro, Cons. Nac. Petróleo, p. 148-162. (CNP, Rel. de 1946).

VIANA, C.F. - 1980 - Cronoestratigrafia dos sedimentos da margem continental brasileira. In: CONGR. BRAS. GEOL., 31, Baln. Camboriú, 1980. Anais... Baln. Camboriú, SBG. v. 2, p.832-843.

VIANA, C.F.; GAMA JR., E.G.; SIMŌES, I.A.; MOURA, J.J.A.; FONSECA, J.R.; ALVES, R.J. - 1971 - Revisão estratigráfica da Bacia do Recôncavo-Tucano. Bol. Tec. Petrobrás, 14(3/4):157-192.

MANUSCRITO 387

Recebido em 01 de setembro de 1986 Revisão aceita em 17 de dezembro de 1986 